\title{
中国蛇类物种丰富度地理格局及其与生态因子的关系
}

\author{
蔡 波 ${ }^{1,2}$, 黄 勇 $^{3}$, 陈跃英 ${ }^{1}$, 胡军华 ${ }^{1}$, 郭宪光 ${ }^{1}$, 王跃招 ${ }^{1,}$, \\ (1. 中国科学院成都生物研究所, 四川 成都 610041; 2. 中国科学院研究生院, 北京 100049; 3. 广西药用植物园, 广西 南宁 530023) \\ 摘要: 物种丰富度地理格局成因是生态学和生物地理学研究重要目标之一。生态假说在解释物种丰富度地理 \\ 格局的成因上受到广泛关注。该文基于 $100 \mathrm{~km} \times 100 \mathrm{~km}$ 空间分辨率研究中国蛇类物种丰富度的地理分布格局, 并 \\ 结合生态假说探讨影响蛇类分布格局的因素。该研究采用主轴邻距法获得基于特征值的空域数据, 并同生态因子 \\ 进行多元回归分析, 结果表明: (1) 中国蛇类物种丰富度在经、纬度上呈现多峰分布格局, 物种丰富度最高的地区 \\ 位于东洋界亚热带、热带, 丰富度较低的地区位于青藏高原、北方草原荒漠、黄淮平原、两湖平原及鄱阳湖平原 \\ 等; (2) 多元回归分析能解释 $56.5 \%$ 的蛇类物种丰富度变化, 分析得出蛇类物种丰富度格局的主要影响因子是归一 \\ 化植被指数、最冷季降水量和年温差。(3) 模型选择结果显示, 在多元回归分析中, $P<0.05$ 的变量 (归一化植被 \\ 指数、最冷季降水量和年温差) 组成的模型是解释蛇类物种丰富度格局的最优模型。这说明蛇类物种丰富度格局 \\ 是由不同生态因子共同作用的结果。基于中国蛇类物种丰富度地理格局成因研究的复杂性, 该文提出在进一步研 \\ 究中, 需重视各假说中影响因子的选择和人类活动的影响, 并在不同空间尺度上对蛇类物种丰富度地理格局进行 \\ 综合分析。
}

关键词: 宏生态学; 生态假说; 生物地理学; 空间分布格局; 能量假说; 生境异质性假说

中图分类号: Q14 文献标志码: A 文章编号: 0254-5853-(2012)04-0343-11

\section{Geographic patterns and ecological factors correlates of snake species richness in China}

\author{
CAI Bo ${ }^{1,2}$, HUANG Yong ${ }^{3}$, CHEN Yue-Ying ${ }^{1}$, HU Jun-Hua ${ }^{1}$, GUO Xian-Guang ${ }^{1}$, \\ WANG Yue-Zhao ${ }^{1, *}$
}

(1. Chengdu Institute of Biology, the Chinese Academy of Science, Chengdu 610041, China; 2. Graduate School of Chinese Academy of Science, Beijing 100049, China; 3. Guangxi Botanical Garden of Medicinal Plants, Nanning 530023, China)

\begin{abstract}
Understanding large-scale geographic patterns of species richness as well its underlying mechanisms are among the most significant objectives of macroecology and biogeography. The ecological hypothesis is one of the most accepted explanations of this mechanism. Here, we studied the geographic patterns of snakes and investigated the relationships between species richness and ecological factors in China at a spatial resolution of $100 \mathrm{~km} \times 100 \mathrm{~km}$. We obtained the eigenvector-based spatial filters by Principal Coordinates Neighbor Matrices, and then analyzed ecological factors by multiple regression analysis. The results indicated several things: (1) species richness of snakes showed multi-peak patterns along both the latitudinal and longitudinal gradient. The areas of highest richness of snake are tropics and subtropical areas of Oriental realm in China while the areas of lowest richness are Qinghai-Tibet Plateau, the grasslands and deserts in northern China, Yangtze-Huai Plain, Two-lake Plain, and the Poyang-lake Plain; (2) results of multiple regression analysis explained a total of $56.5 \%$ variance in snake richness. Among ecological factors used to explore the species richness patterns, we found the best factors were the normalized difference vegetation index, precipitation in the coldest quarter and temperature annual range ; (3) our results indicated that the model based on the significant variables that $(P<0.05)$ uses a combination of normalized difference vegetation index, precipitation of coldest quarterand temperature annual range is the most parsimonious model for explaining the mechanism of snake richness in China. This finding demonstrates that different ecological factors work together to affect the geographic distribution of
\end{abstract}

收稿日期: 2012-03-20; 接受日期: 2012-05-05

基金项目：国家自然科学基金面上项目(NSFC31071892); 中国科学院知识创新工程方向项目(KSCX2-EW-J-22); 科技部基础专项 (2006FY110500-3)

*通信作者(Corresponding author), E-mail: arcib@cib.ac.cn

第一作者简介: 蔡波(1986-), 男, 硕士研究生, 研究方向为生态生物地理学、动物生态学、保护生物学。E-mail: caibo.cd@gmail.com 
snakes in China. Studying the mechanisms that underlie these geographic patterns are complex, so we must carefully consider the choice of impact-factors and the influence of human activities.

Key words: Macroecology; Ecological hypothesis; Biogeography; Spatial distribution patterns; Energy hypothesis; Habitat heterogeneity hypothesis

物种丰富度大尺度地理格局及其成因是生态 学和生物地理学研究的重要目标之一(Gaston, 2000)。目前已有多种假说解释物种丰富度地理格局 的形成机制(Currie, 1991; Gaston, 2000; Hawkins et al, 2003a,b; Rahbek, 2005), 其中, 受到广泛关注的 生态假说(ecological hypothesis)主要包括生产力假 说(productivity hypothesis)、环境能量假说(ambient energy hypothesis)、寒冷忍耐假说(freezing tolerance hypothesis)、水能动态假说 (water-energy dynamic hypothesis)及生境异质性假说 (habitat heterogeneity hypothesis)(Gaston, 2000; Terribile et al, 2009)。生产 力假说认为能量的增加提高了一个地区的净初级 生产力, 导致流向食物网各营养级的能量增加, 保 证了更多个体的存活, 从而提高了物种多样性 (Currie et al, 2004; Hawkins et al, 2003a, b; Wang et al, 2009; Wright, 1983); 环境能量假说认为环境能 量直接影响生物个体的生理调节机制, 从而影响种 群增长进而影响物种丰富度( Currie, 1991; Huang et al, 2011; Turner, 2004; Turner et al, 1987; Wang et al, 2009); 寒冷忍耐假说认为多数物种因受最冷季低 温忍受力影响而不能在更冷的地区生存(Currie et al, 2004; Hawkins, 2001; Hawkins et al, 2003a; Wang et al, 2009); 水能动态假说基于水分对生物能量利用 过程的影响, 认为生物多样性的大尺度分布格局由 水能动态决定 ( Hawkins et al, 2003a; O'Brien, 1993; Wang et al, 2009); 生境异质性假说认为物理因子或 生物因子的复杂性孕育较多生态位, 环境越复杂, 空间异质性程度越高, 小生境类型越多样, 所能支 持的物种数也越多 (Cox \& Moore, 2010; Jiang et al, 1997; Kerr \& Packer, 1997; Pianka, 1966)。但越来越 多的研究表明物种丰富度地理格局的形成机制很 复杂, 不能仅由某一个假说来解释(Currie，1991; Hawkins et al, 2003a; Rahbek, 2005)。

中国疆域广阔, 跨越古北与东洋两大动物区 系。第三纪晚期以来发生的地质事件, 特别是印度 板块北移与青藏高原隆起, 使得区域内地理环境复 杂, 气候多样, 物种(包括蛇类)多样性丰富(Zhang,
1999)。截止 2012 年 2 月, 我国境内记录蛇类 222 种( Gong et al, 2010; Guo et al, 2008; Guo \& Wang, 2011; Guo et al, 2011; Huang et al, 2012; Jiang \& Zhao, 2009; Luo et al, 2010; Malhotra et al, 2011; Rao \& Zhao, 2005; Vogel \& David, 2010; Vogel \& Luo, 2011; Yang et al, 2011a, b; Zhang et al, 2011a; Zhang et al, 2011b; Zhao, 2006; Zhao \& Adler, 1993), 约占 全球蛇类物种数的 $7 \%$ (http://www.reptile -database.org)。关于中国蛇类物种多样性, 早在三千 年前的《山海经》中就有记载, 其分布格局与生态 因子关系则在 20 世纪 80 年代开始受到关注(Shen, 1985)。尽管在一些两栖爬行动物的分布格局研究中 涉及蛇类，但尚无针对整个中国区域蛇类分布格局 的相关研究, 这与该类群所具有的独特进化地位很 不相称。

不同类群物种具有不同的生理特性，适应不同 的生态环境，其分布格局及其成因也有所不同 (Gaston, 2000; Lin et al, 2009), 特别在全球气候变 化背景下, 更需要了解某一类群的物种多样性分布 格局与生态因子关系机制, 以利于生物多样性保 护。因此, 本文将探讨中国蛇类物种丰富度分布格 局及其影响因素, 结合生态假说分析其成因, 为蛇 类多样性保护提供科学依据。

\section{1 材料和方法}

\section{1 物种数据}

以爬行动物数据库 (http://www.reptiledatabase.org)和《中国蛇类》(Zhao, 2006)的分类系统 为依据, 本研究收集中国蛇类物种信息, 包括采集 地点经纬度、生境与海拔等。数据主要来源于中国 科学院两栖爬行动物标本馆[Museum of Herpetology, Chengdu Institute of Biology (CIB), Chinese Academy of Sciences], 以及 《中国动物志·有鳞目. 蛇亚目》《《中 国蛇类》和在以下杂志公开发表的文献，如 《Zootaxa》、《Bonn Zoological Bulletin》、 《Asian Herpetological Research》、《两栖爬行动物学报》、 《动物学研究》、《四川动物》、《动物分类学报》等。 
若资料中记录有经、纬度数据，则采用原资料的经、 纬度; 若无, 则根据资料记载地点(至少到县级行政 区划)使用 Google Earth 查找物种分布的经、纬度。
另外，我们还邀请相关专家对原始数据审阅、更新和 修正。数据整理截止 2011 年 8 月, 共获得 19575 条 记录(图 1), 最终构建了中国 219 种蛇类分布数据库。

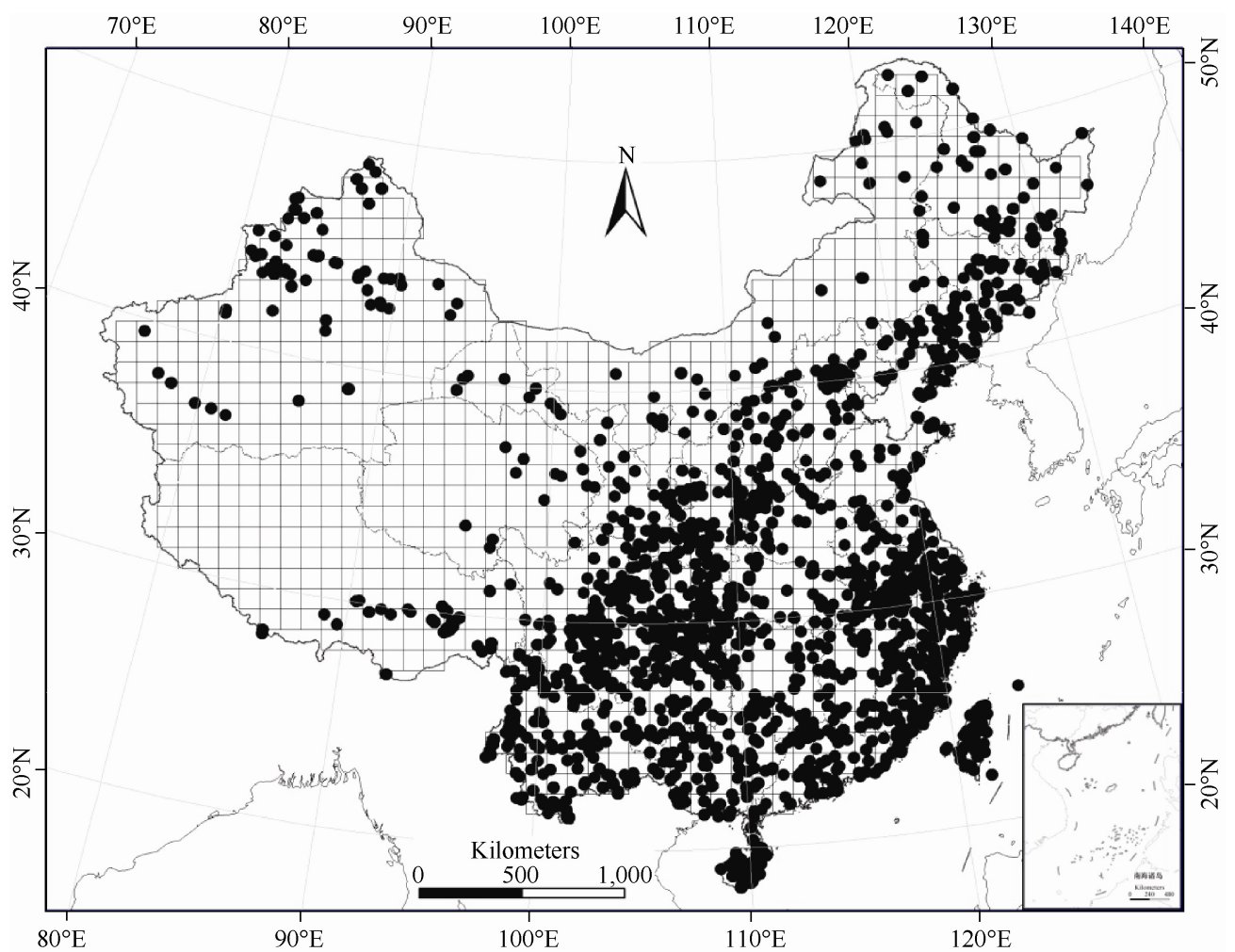

图 1 基于标本馆记录和各种文献收集的中国蛇类分布点图

Fig. 1 Raw sample point of snakes based on museum collections and published literature 地图投影基于 Alberts Equal-Area Conic Projection (双标准纬线: N25和 $\mathrm{N} 47^{\circ}$, 中央经度 $\mathrm{E} 105^{\circ}$ )。

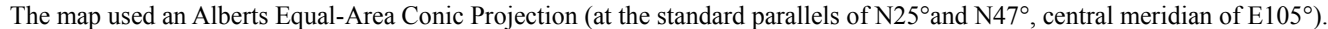

\section{2 生态数据}

本研究共采用 31 个生态因子作为自变量(表 1), 并基于生态假说将其分为 5 组: 生产力假说、环境 能量假说、寒冷忍耐假说、水能动态假说和生境异 质性假说(Currie, 1991; Hawkins et al, 2003a; Kerr \& Packer, 1997; Terribile et al, 2009; Wang et al, 2009)。 相关假说和生态因子如下:

生产力假说一般用实际蒸散量(mean annual actual evapotranspiration, AET) (Currie \& Paquin, 1987; Huang et al，2011) 和归一化植被指数 (normalized difference vegetation index, NDVI) (Evans et al, 2006; Huang et al, 2011)衡量。AET 的空 间分辨率为 $30^{\prime}$, 数据来源于 http://www.grid.unep.ch/ data/grid/gnv183.html。NDVI 数据来自 1998-2008 年, 空间分辨率为 $1 \mathrm{~km}^{2}$, 来源于 $\mathrm{http}: / /$ westdc. westgis.ac.cn。

环境能量假说采用温度及相关指标衡量(Currie,
1991; Huang et al, 2011; Turner et al, 1987; Wang et al，2009)。本文采用年均温 $\left({ }^{\circ} \mathrm{C}\right.$ )(annual mean temperature, $\left.T_{\text {mean }}\right) 、$ 等温性 $\left({ }^{\circ} \mathrm{C}\right)$ (isothermality, ISO)、 温度季节性变化 $\left({ }^{\circ} \mathrm{C}\right)$ (temperature seasonality, TS) 、 风速 $(\mathrm{m} / \mathrm{s})($ mean annual wind, WIND) 衡量, 其中 $T_{\text {mean }}$ ISO、TS 数据来自 1961-1990 年, 空间分辨 率为 $30 "\left(\sim 1 \mathrm{~km}^{2}\right)$, 来源于 http://www.worldclim. org。WIND 来自 1981-1996 年, 空间分辨率为 500 $\mathrm{m}^{2}$ ，来源于 $\mathrm{http}: / / \mathrm{www} . g e o d a t a . c n / P o r t a l$ 。

寒冷忍耐假说常用最冷季均温、最冷月均温或 年最低温等极端低温相关指标来衡量(Hawkins, 2001; Hawkins et al, 2003a; Wang et al, 2009), 又因 物种对低温的耐受能力受所处环境温度及其变化 影响，因此，同时也需要采用一般环境温度、温差 指标来衡量(Ricklefs \& Schluter, 1993; Wiens \& Donoghue，2004)。本文采用年最高温 $\left({ }^{\circ} \mathrm{C}\right)$ (mean annual highest temperature, $\left.T_{\max }\right) 、$ 年最低温 $\left({ }^{\circ} \mathrm{C}\right)$ 
表 1 表征各个假说的生态因子

Tab. 1 Tested ecological factors associated with the five hypotheses

\begin{tabular}{|c|c|}
\hline 生态假说 Ecological hypothesis & 生态因子 Ecological factors \\
\hline $\begin{array}{l}\text { 生产力假说 } \\
\text { Productivity hypothesis }\end{array}$ & 实际蒸散量 $(\mathrm{mm} / \mathrm{y})(A E T)$ 、归一化植被指数 $(N D V I)$ \\
\hline $\begin{array}{l}\text { 环境能量假说 } \\
\text { Ambient energy hypothesis }\end{array}$ & 年均温 $\left({ }^{\circ} \mathrm{C}\right)\left(T_{\text {mean }}\right)$ 、等温性 $(\mathrm{ISO})$ 、温度季节性变化 $(T \mathrm{~S})$ 、风速 $(\mathrm{m} / \mathrm{s})(W I N D)$ \\
\hline $\begin{array}{l}\text { 寒冷忍耐假说 } \\
\text { Freezing tolerance hypothesis }\end{array}$ & $\begin{array}{l}\text { 年最高温 }\left({ }^{\circ} \mathrm{C}\right)\left(T_{\max }\right) \text { 、年最低温 }\left({ }^{\circ} \mathrm{C}\right)\left(T_{\min }\right) 、 \text { 最冷月均温 }\left({ }^{\circ} \mathrm{C}\right)\left(T \mathrm{CM}_{\text {mean }}\right) 、 \text { 最热月均温 }\left({ }^{\circ} \mathrm{C}\right)\left(T \mathrm{WM}_{\text {mean }}\right) \text { 、最潮 } \\
\text { 季均温 }\left({ }^{\circ} \mathrm{C}\right)\left(T \text { Wet } \mathrm{Q}_{\text {mean }}\right) \text { 、最旱季均温 }\left({ }^{\circ} \mathrm{C}\right)\left(T \mathrm{DQ}_{\text {mean }}\right) \text { 、最冷季均温 }\left({ }^{\circ} \mathrm{C}\right)\left(T \mathrm{CQ}_{\text {mean }}\right) \text { 、最热季均温 } \\
\left({ }^{\circ} \mathrm{C}\right)\left(T \text { WarmQ } \mathrm{Q}_{\text {mean }}\right) \text { 、年温差 }\left({ }^{\circ} \mathrm{C}\right)(T \mathrm{AR}) 、 \text { 日温差 }\left({ }^{\circ} \mathrm{C}\right)(T \mathrm{DR})\end{array}$ \\
\hline $\begin{array}{l}\text { 水能动态假说 } \\
\text { Water-energy dynamic hypothesis }\end{array}$ & $\begin{array}{l}\text { 年均温 }\left({ }^{\circ} \mathrm{C}\right)\left(T_{\text {mean }}\right) \text { 、实际蒸散量 }(\mathrm{mm} / \mathrm{a})(A E T) \text { 、潜在蒸散量 }(\mathrm{mm} / \mathrm{a})(P E T) \text { 、年降水量 }(\mathrm{mm} / \mathrm{a})(A P) \text { 、最潮月降 } \\
\text { 雨量 }(\mathrm{mm} / \mathrm{a})(P W M) \text { 、最早月降雨量 }(\mathrm{mm} / \mathrm{a})(P D M) \text { 、季节性降水量 }(\mathrm{mm} / \mathrm{a})(P S) \text { 、最潮季降水量 } \\
(\mathrm{mm} / \mathrm{a})(P \text { WetQ }) \text { 、最旱季降水量 }(\mathrm{mm} / \mathrm{a})(P D Q) \text { 、最冷季降水量 }(\mathrm{mm} / \mathrm{a})(P C Q) \text { 、最热季降水量 }(\mathrm{mm} / \mathrm{a}) \\
(P W a r m Q) 、 \text { 相对湿度 }(\%)(R E H) 、 \text { 潮湿天数 }(\mathrm{mm} / \mathrm{a})(W D)\end{array}$ \\
\hline $\begin{array}{l}\text { 生境异质性假说 } \\
\text { Habitat heterogeneity hypothesis }\end{array}$ & 土地覆盖类型数(LUCC)、平均海拔(ELE mean $) 、$ 最高海拔 $\left(E^{2} E_{\max }\right) 、$ 最低海拔 $\left(\mathrm{ELE}_{\min }\right)$ \\
\hline
\end{tabular}

(mean annual lowest temperature, $T_{\min }$ )、最冷月均温 $\left({ }^{\circ} \mathrm{C}\right)\left(\right.$ temperature of coldest month, $\left.T C \mathrm{M}_{\text {mean }}\right) 、$ 最热月 均温 $\left({ }^{\circ} \mathrm{C}\right)$ (temperature of warmest month, $\left.T \mathrm{WM}_{\text {mean }}\right)$ 、 最潮季均温 $\left({ }^{\circ} \mathrm{C}\right)($ mean temperature of wettest quarter, $T$ WetQ $\left.Q_{\text {mean }}\right)$ 、最早季均温 $\left({ }^{\circ} \mathrm{C}\right)($ mean temperature of driest quarter, $\left.T \mathrm{DQ}_{\text {mean }}\right)$ 、最冷季均温 $\left({ }^{\circ} \mathrm{C}\right)($ mean temperature of coldest quarter, $\left.T \mathrm{CQ}_{\text {mean }}\right)$ 、最热季均温 $\left({ }^{\circ} \mathrm{C}\right)$ (mean temperature of warmest quarter, $T$ WarmQ $\left.Q_{\text {mean }}\right) 、$ 年温差 $\left({ }^{\circ} \mathrm{C}\right)$ (temperature annual range, TAR)、日温差 $\left({ }^{\circ} \mathrm{C}\right)[$ mean diurnal range-mean of monthly (max temp-min temp), TDR]衡量, 这些数据 来自 1961-1990 年, 空间分辨率为 $30^{\prime \prime}\left(\sim 1 \mathrm{~km}^{2}\right)$, 来源于 http://www.worldclim.org。

水能动态假说是基于水分对生物能量利用过 程的影响, 认为生物多样性大尺度分布格局由水能 动态决定, 通常用蒸散量、温度、降水量和湿度相 关指标来衡量(Hawkins et al, 2003a; Wang et al, 2009)。本文采用年均温 $\left({ }^{\circ} \mathrm{C}\right)($ mean annual temperature, $\left.T_{\text {mean }}\right) 、$ 实际蒸散量 $(\mathrm{mm} / \mathrm{y})$ (actual evapotranspiration, $A E T) 、$ 潜在蒸散量 $(\mathrm{mm} / \mathrm{a})$ (potential evapotranspiration, $P E T)$ 、年降水量 $(\mathrm{mm} / \mathrm{a})($ mean annual precipitation, $A P)$ 、最潮月降雨量 $(\mathrm{mm} / \mathrm{a})$ (precipitation of wettest month, $P \mathrm{WM})$ 、最早月降雨量 $(\mathrm{mm} / \mathrm{a})$ (precipitation of driest month, $P D M)$ 、季节性降水量 $(\mathrm{mm} / \mathrm{a})$ [precipitation seasonality (coefficient of variation), $\mathrm{PS}$ ]、最潮季降水量 $(\mathrm{mm} / \mathrm{a})$ (precipitation of wettest quarter, $P$ WetQ)、最旱季降水量 $(\mathrm{mm} / \mathrm{a})$ (precipitation of driest quarter, $P D Q)$ 、最冷季降水量 $(\mathrm{mm} / \mathrm{a})$ (precipitation of coldest quarter, $P C Q)$ 、最热季
降水量 (mm/a)(precipitation of warmest quarter, $P$ WarmQ)、相对湿度(\%)(relative humidity, REH)、 潮湿天数 $(\mathrm{mm} / \mathrm{a})$ (wet-days, Number days with $>0.1$ mm rain per month, WD)衡量。其中 PET 的空间分辨 率为 $30^{\prime}$, 来源于 http://www.grid.unep.ch/data/ grid/gnv183.html。AP、PWM、PDM、PS、PWetQ、 $P D Q 、 P C Q 、 P W a r m Q$ 数据来自 1961-1990 年, 空 间分辨率为 30 " $\left(\sim 1 \mathrm{~km}^{2}\right)$, 来源于 http://www. worldclim.org。REH、WD 数据来自 1961-1990 年, 空间分辨率为 $10^{\prime}$, 来源于 http://www.geodata.cn/ Portal。

生境异质性假说常用生境类型或者海拔指标 衡量(Currie, 1991; Huang et al, 2011; Kerr \& Packer, 1997)。本文采用每个栅格的土地覆盖类型数 (land use and land cover change, LUCC)、平均海拔(mean elevation, $\mathrm{ELE}_{\text {mean }}$ )、最高海拔(maximum elevation, $E L E_{\max }$ )、最低海拔(minimum elevation, $\mathrm{ELE}_{\min }$ )。海 拔数据来源 http://eros.usgs.gov, 空间分辨率为 $30^{\prime}$ 。 植被类型数据来源国家自然科学基金委员会“中国 西部环境与生态科学数据中心” http://westdc. westgis.ac.cn, 空间分辨率为 $1 \mathrm{~km}^{2}$ 。

\section{3 统计分析}

不同空间尺度或面积对物种分布格局的形成有 重要影响(He \& Legendre, 1996; Willis \& Whittaker, 2002)。为了消除空间尺度或面积对物种分布格局的 影响，本研究将中国国土划分为 $100 \mathrm{~km} \times 100 \mathrm{~km}$ 的 栅格系统(Huang et al, 2011); 为了防止海岸线和边 界地区不完整栅格影响后续统计分析，去除了不足 完整桶格面积 75\%的栅格(Huang et al, 2011); 为了 
消除岛屿的影响(Connor \& McCoy, 2001; Schall \& Pianka，1978), 去除所有岛屿栅格。本研究利用 ArcGIS 软件将蛇类物种分布数据生成每个物种的 Arc/Info 栅格图，有某一物种分布的栅格赋值为“1”, 无某一物种分布的栅格赋值为“ “””, 然后叠加所有物 种的栅格图以生成物种丰富度格局，最后投影为 Alberts Equal-Area Conic Projection (双标准纬线:
$\mathrm{N} 25^{\circ}$ 和 $\mathrm{N} 47^{\circ}$, 中央经度 $\mathrm{E} 105^{\circ}$ )。同时, 所有生态因 子投影重采样为 $100 \mathrm{~km} \times 100 \mathrm{~km}$ 并提取数据。

由于生态因子间的强相关性会给后续多元回归 分析带来偏差, 因此研究中尽可能选择相关系数低 的变量并且每个假说至少有一个变量代表(Huang et $\mathrm{al}, 2011)$ 。于是, 在 SPSS 软件中对生态因子进行两两 之间相关分析后, 选择相关系数 $<0.7$ 的变量 (表 2 )。

表 2 生态因子的相关矩阵 $(r<0.7)$

Tab. 2 Correlation matrix of ecological factors $(r<0.7)$

\begin{tabular}{cccccccc}
\hline & ELEmin & WIND & ISO & TAR & PS & PCQ & NDVI \\
\hline ELEmin & 1 & $0.137^{* *}$ & $0.611^{* *}$ & $-0.089^{* *}$ & $0.431^{* *}$ & $-0.390^{* *}$ & $-0.555^{* *}$ \\
WIND & & 1 & $-0.224^{* *}$ & $0.497^{* *}$ & $0.346^{* *}$ & $-0.284^{* *}$ & $-0.483^{* *}$ \\
ISO & & & $-0.518^{* *}$ & $0.283^{* *}$ & $-0.188^{* *}$ & $-0.112^{* *}$ \\
TAR & & & 1 & $0.357^{* *}$ & $-0.546^{* *}$ & $-0.510^{* *}$ \\
PS & & & & 1 & $-0.675^{* *}$ & $-0.406^{* *}$ \\
PCQ & & & & & 1 & $0.644^{* *}$ \\
NDVI & & & & & & 1 \\
\hline
\end{tabular}

**: 相关性在 0.01 的水平显著(双尾)。Correlation is significant at the 0.01 level (2-tailed).

*: 相关性在 0.05 的水平显著(双尾)。Correlation is significant at the 0.05 level (2-tailed).

统计分析在 SAM v4.0 (Spatial Analysis in Macroecology, http://www.ecoevol.ufg.br/sam) (Rangel et al, 2006, 2010)软件中完成。为了消除回 归残差空间自相关, 本研究采用主轴邻距法(PCNM, principal coordinates neighbor matrices)获得基于特 征值的空域数据(eigenvector-based filters)并与生态 因子一起进行多元回归分析, 该方法能有效降低回 归残差空间自相关(Diniz-Filho \& Bini, 2005)。为降 低空间自相关性, 本文选择最小残差的 Moran's $I$ 指数的空域文件(filters)(Diniz-Filho \& Bini, 2005), 将其与生态因子组成多元回归模型。Moran's $I$ 指数 取值范围为 $-1 \sim 1$, “ -1 ” 意味着强烈的负空间自相 关，“ 0 ” 意味着无相关性， “ 1 ” 意味存在强烈的 正空间自相关。该多元回归分析包括了空间因素, $r^{2}$ 由三部分组成: 仅生态因子(predictors only)、仅空 域(filters only)、两者(生态因子和空域)(predictors+ filters)。

为了探讨 5 个假说对中国蛇类物种丰富度分布 格局的解释程度, 本研究对各假说包含的所有变量 采用主轴邻距法分别进行多元回归分析, 同时另增 加两个混合模型: 大混合模型(所有变量), 小混合 模型(多元回归分析中 $P<0.05$ 的变量)。采用样本大 小矫正过的赤池信息准则( $\mathrm{AICc}$ )来衡量模型拟合度 优良性。最小 AICc 值的模型是最简约或优先考虑
的模型，是在模型构建中偏差和精度之间最优化的 权衡(Burnham \& Anderson, 1998)。当所有模型的 $\mathrm{AICc}$ 值都很接近时, 用候选模型和最优模型之差 $(\triangle \mathrm{AICc})$ 衡量相关模型拟合度。 $\triangle \mathrm{AICc}$ 越小, 候选模 型越接近最优模型。即, 当 $\Delta \mathrm{AICc} \leqslant 2$ 时, 数据强力 支持该模型；当 $4 \leqslant \Delta \mathrm{AICc} \leqslant 7$ 时，数据一定程度支 持该模型; 当 $\Delta \mathrm{AICc}>10$ 时，数据不支持该模型。 使用赤池权重(Akaike weights, $\mathrm{w}_{\mathrm{i}}$ ) 估计的模型平均 数来解决模型选择的不确定性 (Burnham \& Anderson, 1998)。

\section{2 结 果}

\section{1 物种丰富度地理格局}

由图 2 可见中国蛇类物种丰富度热点地区在横 断山脉南部、南岭、武夷山脉、大娄山一巫山山脉、 青藏高原东南缘、秦岭-大巴山脉、藏南河谷(雅鲁 藏布江下游地区), 以及北方的长白山脉、小兴安岭 和西部的天山山脉西部等。中国蛇类物种丰富度并 不随纬度升高而单调降低, 而是在 $\mathrm{N} 22^{\circ} \sim 28^{\circ}$ 为最 高峰, 在 $\mathrm{N} 28^{\circ} \sim 37^{\circ}$ 随纬度升高而显著降低, 在 $\mathrm{N} 37^{\circ}$ 有一个低谷(图 $3 \mathrm{~A}$ ); 在 $\mathrm{E} 75^{\circ} \sim 90^{\circ}$ 变化不大, 在 $\mathrm{E} 90^{\circ} \sim 110^{\circ}$ 随着经度升高而上升, 在 $\mathrm{E} 110^{\circ} \sim$ $128^{\circ}$ 随着经度升高而降低, 在 $\mathrm{E} 128^{\circ}$ 之后随着经度 升高而上升，丰富度最高值位于 $\sim \mathrm{E} 110^{\circ}$ 处（图 


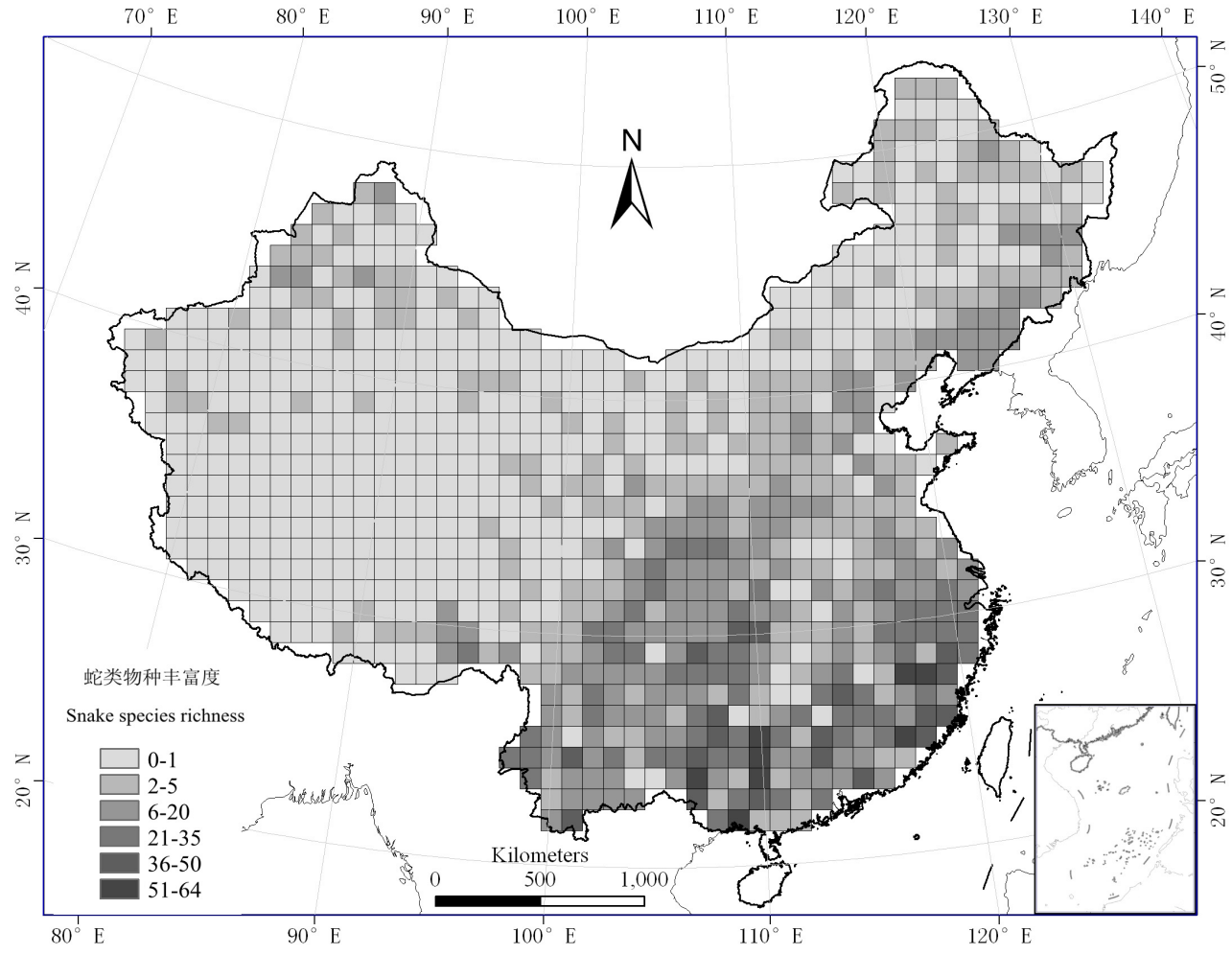

图 2 中国蛇类物种丰富度栅格图 $(100 \mathrm{~km} \times 100 \mathrm{~km})$

Fig. 2 Grid map of snake species richness patterns in China at $100 \mathrm{~km}$ spatial resolution

3B)。结合图 2 可知中国蛇类物种丰富度最高的地 区出现东洋界亚热带、热带地区, 物种丰富度较低 的地区在青藏高原、北方草原荒漠地区、黄淮平原、 两湖平原、鄱阳湖平原等地。
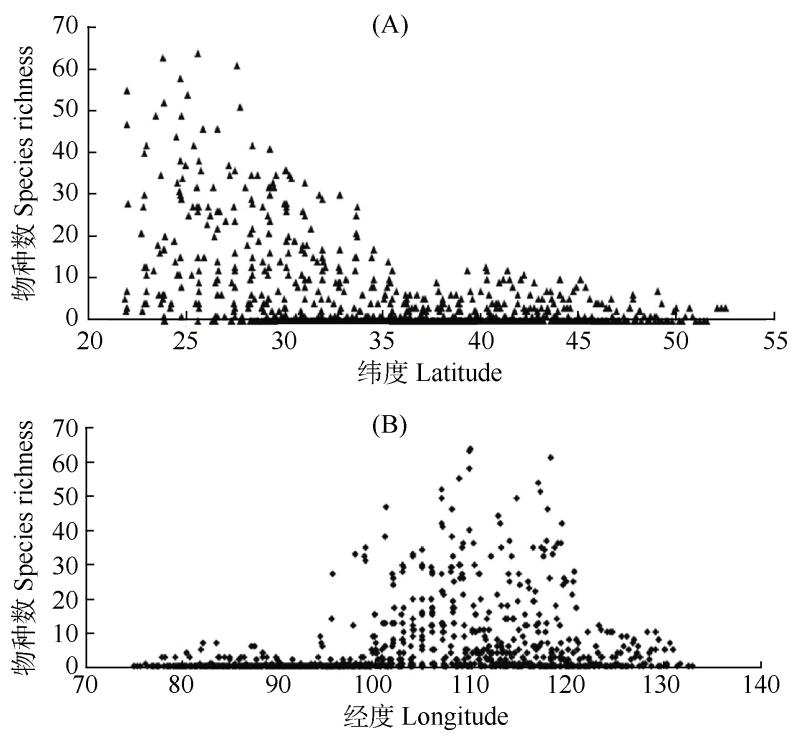

图 3 中国蛇类物种丰富度与纬度 $(\mathrm{A})$ 、经度 $(\mathrm{B})$ 关系 $(100 \mathrm{~km} \times 100 \mathrm{~km})$

Fig. 3 Relationship of snake richness $(100 \mathrm{~km} \times 100 \mathrm{~km})$ in China with (A) latitude and (B) longitude

\section{2 物种丰富度地理格局与生态因子的关系}

主轴邻距法分析的截尾距离(truncation distance) 为 $142.265 \mathrm{~km}$ 。选择最小残差的 Moran's $I$ 指数的 空域文件将其与生态因子组成多元回归模型, 有效 消除了空间自相关性(图 4)。

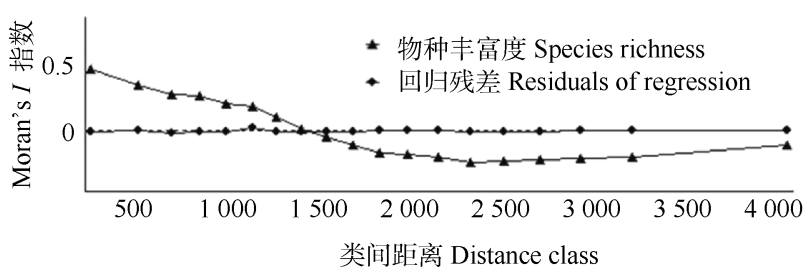

图 4 蛇类物种丰富度和多元回归残差的 Moran's $I$ 指数图

Fig. 4 Moran's I correlogram for snake species richness and the residuals of multiple regression with ecological predictors

使用空间特征值模型的多元回归分析能够解 释蛇类物种丰富度总体 $56.5 \%$ 的变化 $\left(r^{2}=0.565\right.$; $F=66.86 ; P=0)$, 仅生态因子解释了 $39.9 \%$, 仅空域 解释了 $8.6 \%$, 两者(生态因子和空域)共同解释了 $8.1 \%$ 。在所有生态因子中, 归一化植被指数和最冷 季降水量是影响中国蛇类物种丰富度最大的因子, 且它们均与中国蛇类物种丰富度呈正相关, 年温差 
是影响中国蛇类物种丰富度次大的因子，与中国蛇 类物种丰富度呈负相关(表 3)。

\section{3 生态假说对物种丰富度地理格局的解释}

基于赤池信息量准则的模型选择方法，小混合 模型(多元回归分析中 $P<0.05$ 的变量)的 $\triangle \mathrm{AICc}$ 最低, 赤池权重为 1 (表 4), 是解释中国蛇类物种丰富度格 局的最优模型。其他模型(如: 大混合模型、生境异 质性假说、生产力假说、环境能量假说、寒冷忍耐 假说、水能动态假说) $\Delta \mathrm{AICc}$ 均 $>10$, 赤池权重也 很低。

表 3 中国蛇类物种丰富度与生态因子的多元回归分析

Tab. 3 Snake richness regressed against environmental variables in China

\begin{tabular}{lccc}
\hline \multicolumn{1}{c}{$\begin{array}{c}\text { 生态因子 } \\
\text { Ecological factors }\end{array}$} & $b$ & $t$ & $P$ \\
\hline 最冷季降水量 PCQ & 0.098 & 8.915 & $<0.001$ \\
归一化植被指数 NDVI & 10.934 & 3.345 & $<0.001$ \\
年温差 TAR & -0.171 & -2.557 & 0.011 \\
季节性降水量 PS & 0.027 & 1.437 & 0.151 \\
最低海拔 ELE min $_{\text {风速 WIND }}$ & $<0.001$ & -0.907 & 0.365 \\
等温性 ISO & -0.161 & -0.385 & 0.700 \\
\hline
\end{tabular}

$b$ : 直线回归方程系数。The linear regression coefficients.

未显示基于主轴邻距法而获得空域数据值 (Filters obtained by Principal Coordinates Neighbor Matrices are not shown $)\left(r^{2}=0.565, F_{(17.874)}=66.86\right.$, $P=0$ )。

$t$ : 直线回归 $\mathrm{t}$ 检验值。The linear regression $\mathrm{t}$-test values.

3 讨 论

\section{1 中国蛇类物种丰富度地理格局}

物种丰富度具有空间异质性特征(Gaston, 2000), 蛇类也不例外。中国区域蛇类物种丰富度最 高的地区在东洋界亚热带、热带地区，如：武夷山 脉、横断山脉南部、南岭、藏南河谷(雅鲁藏布江下 游地区)、大娄山一巫山山脉、青藏高原东南缘和秦 岭-大巴山脉(图 2)。这些地区均为南方山区，与中 国最冷季降雨量、归一化植被指数高的地区(图 5) 高度重叠。另外北方丰富度较高地区为长白山脉、 小兴安岭、天山山脉西部等地(图 2), 这些地区的共 同特点也是山区，与北方地区归一化植被指数、年 均温高的地区(图 5)重叠较多。青藏高原、北方草原 荒漠地区、大兴安岭地区是蛇类物种丰富度低的地 区，极端严寒或干旱，与最冷季降雨量、归一化植 被指数、年均温低的地区(图 5)重叠程度高。最冷季 降水量、归一化植被指数与蛇类物种丰富度呈正相 关。最冷季降水量高能有效保证这些地区在蛇类冬 眠期间有足够的水分支撑蛇类捕食对象的生存，并 保证蛇类冬眠所需环境湿度, 帮助幼蛇顺利度过冬 眠期; 归一化植被指数高能促进蛇类食物链下端的 动物大量生长繁殖, 增加蛇类数量和种数。年温差 则与蛇类物种丰富度呈负相关。虽然冬眠是蛇类有 效的体温调节机制，但作为冷血动物，蛇类的最适 气温范围是 $20 \sim 30{ }^{\circ} \mathrm{C}($ Zhao, 2006), 过大温差会阻 碍蛇类生长发育(Sun, 2001), 因此年温差高的地区

表 4 模型选择 ( $K$ 表示模型变量数, 不包括截距; $w_{i}$ 表示权重 $)$

Tab. 4 Summary of the model selection approach based on AICc $w_{i}$ was the Akaike weight (K was the number of variables of the model, not including intercept)

\begin{tabular}{|c|c|c|c|c|c|}
\hline $\begin{array}{c}\text { 生态假说 } \\
\text { Ecological hypothesis }\end{array}$ & $r^{2}$ & $\mathrm{AICc}$ & $\triangle \mathrm{AICc}$ & $K$ & $w_{i}$ \\
\hline $\begin{array}{c}\text { 大混合模型 } \\
\text { Big mixed model }\end{array}$ & 0.57 & 6085.32 & 40.89 & 31 & 0.00 \\
\hline $\begin{array}{c}\text { 生境异质性假说 } \\
\text { Habitat heterogeneity hypothesis }\end{array}$ & 0.56 & 6084.68 & 40.26 & 4 & 0.00 \\
\hline $\begin{array}{c}\text { 生产力假说 } \\
\text { Productivity hypothesis }\end{array}$ & 0.56 & 6069.74 & 25.31 & 2 & 0.00 \\
\hline $\begin{array}{c}\text { 环境能量假说 } \\
\text { Ambient energy hypothesis }\end{array}$ & 0.56 & 6069.61 & 25.18 & 4 & 0.00 \\
\hline $\begin{array}{c}\text { 寒冷忍耐假说 } \\
\text { Freezing tolerance hypothesis }\end{array}$ & 0.57 & 6065.40 & 20.97 & 10 & 0.00 \\
\hline $\begin{array}{c}\text { 水能动态假说 } \\
\text { Water-energy dynamic hypothesis }\end{array}$ & 0.56 & 6064.55 & 20.12 & 13 & 0.00 \\
\hline $\begin{array}{c}\text { 小混合模型 } \\
\text { Small mixed model based on the significant } \\
\text { variables }(P<0.05) \text { from the multiple regression }\end{array}$ & 0.57 & 6044.43 & 0.00 & 3 & 1.00 \\
\hline
\end{tabular}



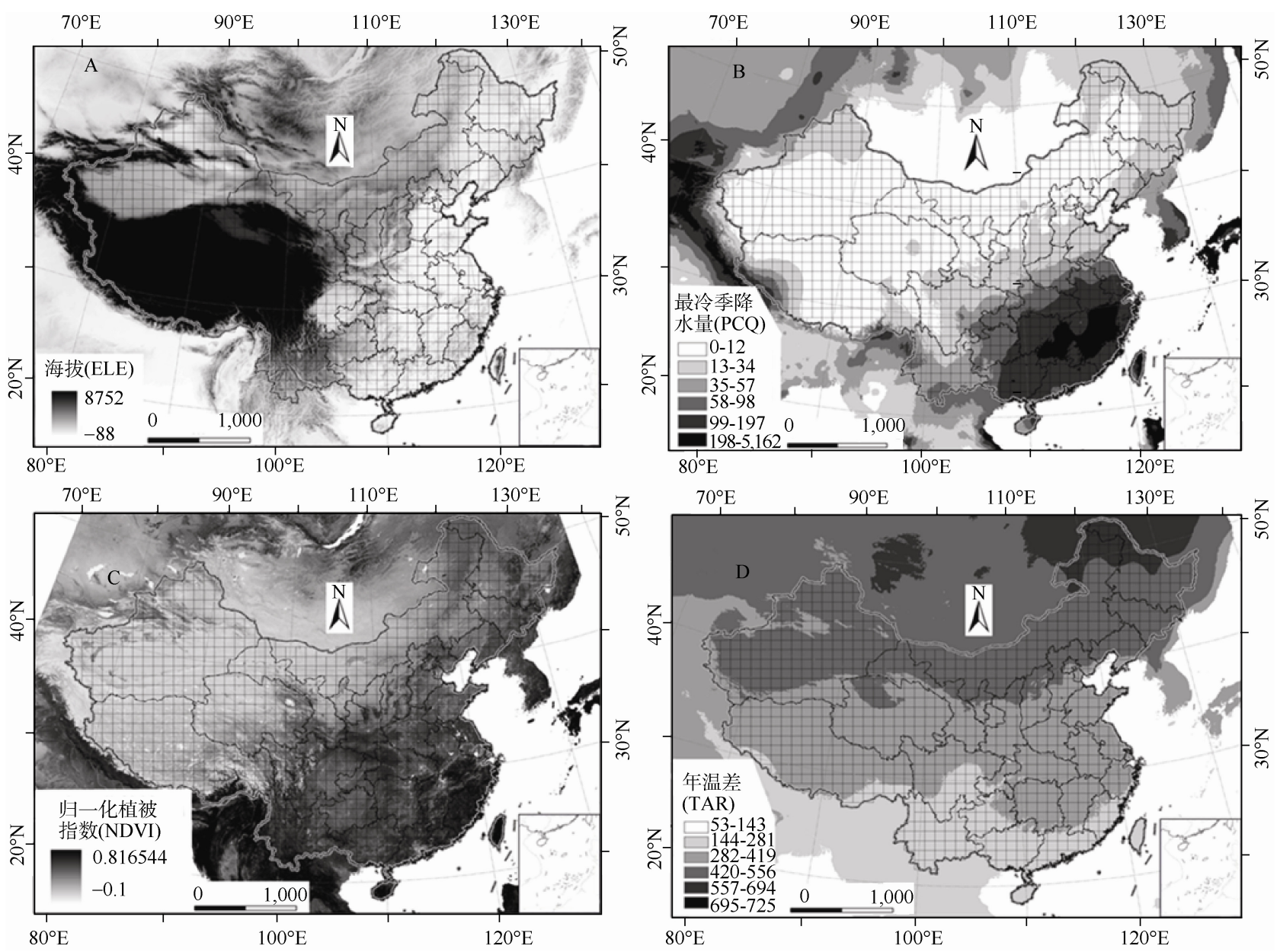

图 5 中国部分生态因子分布图

Fig. 5 Maps of some ecological factors in China A) 海拔(ELE)；B）最冷季均温(PCQ)；C）归一化植被指数(NDVI)；D）年温差(TAR)。

A) Elevation (ELE); B) Precipitation of coldest quarter (PCQ); C) Normalized difference vegetation index (NDVI); D) Temperature annual range (TAR).

蛇类物种丰富度低, 年温差低的地区蛇类物种丰富 度高。

采用主轴邻距法的多元回归分析结果与海拔、 最冷季降水量分布图、年温差分布图具有良好的对 应关系，但局部区域除外，如：东洋界的黄淮平原、 两湖平原、鄱阳湖平原等区域蛇类物种丰富度很 低。这些区域的蚚蜴类、哺乳类物种丰富度也低(Lin et al, 2009; Huang et al, 2011)。原因可能是这些区域 历史上受河患影响严重且农业发达(Gong, 2002; Lin \& Mo, 2011; Zhao et al, 2007)。中国爬行动物濒 危的主要原因是食用和医用造成过度利用, 乱采滥 伐导致生境破碎化, 污水和农药污染(Li \& Wllcove, 2005)。因此这些地区蛇类物种丰富度低, 除了河患 导致外, 还可能是由人类影响所致。具体原因有待 进一步研究。
中国蛇类物种丰富度分布格局与蚚蜴类较为 一致(Huang et al, 2011), 但也存在细微差异, 较明 显的地区在北方草原荒漠和天山山脉西部地区。中 国蚚蜴类物种丰富度格局与年均霜期呈负相关，与 海拔、植被类型数及潮湿天数频率呈正相关(Huang et al, 2011), 而年均霜期、植被类型数及潮湿天数频 率与本研究中所选的蛇类各生态因子相关性很高, 海拔相关性相对较低(表 2), 海拔变幅对蚚蜴影响 显著而对蛇类不显著，与 Shen (1985)的结论一致。 这可能是蛇类、蚚蜴类在这些区域的物种丰富度存 在微小差异的原因之一; 其次可能是由于两类群本 底资料调查不一致所致, 因而有待进一步研究。

\section{2 中国蛇类物种丰富度地理格局的成因及其复 杂性}

生态假说中，除去生境异质性假说之外的假说 
均属于能量假说(energy hypothesis), 该假说认为气 候的能量变化在初期产生了全球丰富度梯度, 能量 可利用性导致并维持物种丰富度梯度(Hawkins et al, 2003a; von Humboldt, 1808)。Hawkins et al (2003a) 研究得出能量组成的气候模型能更好地解释大尺 度丰富度格局, Guisan \& Hofer (2003)也认为中等尺 度能量组成的气候模型比地形模型(地形为生境异 质性假说的成分之一) 更能解释爬行动物物种丰富 度格局, 而生境异质性假说很难在大尺度上解释爬 行动物空间分布格局(Kiester, 1971; Rodríguez et al, 2005)。但也存在其他观点。中国爬行动物物种丰富 度格局成因研究中, 有的既支持生境异质性假说又 支持能量假说(Huang et al, 2011; Qian et al 2007; Shen，1985)，有的仅支持能量假说(Fu et al，2007; Qian et al, 2007; Wang, 2004)。

中国蛇类物种丰富度格局的强影响因子为最 冷季降水量和归一化植被指数。最冷季降水量与蛇 类物种丰富度分布格局呈正相关, 该研究结果支持 水能动态假说。美洲的珊瑚蛇属 (Terribile \& Diniz-Filho, 2009)和中国爬行动物( Fu et al, 2007; Qian et al, 2007; Wang, 2004)相关研究也支持该假 说。该假说主要基于水分对生物体能量利用过程的 影响(Wang et al, 2009), 能有效解释整个地球生物 多样性梯度(Hawkins et al, 2003a), 但对动物的影响 可能是通过对植物生产力和生物量的影响而间接 实现(Hawkins et al, 2003a)。归一化植被指数对蛇类 丰富度格局的影响则一定程度上证明了这种间接 性。NDVI 是生产力假说的重要内容, 本研究表明 NDVI 在一定程度支持生产力假说, 通过控制区域 内的蛇类食物数量来控制蛇类种群密度, 进而影响 其物种丰富度水平。而研究中代表生境异质性假说 的土地覆盖类型数、平均海拔、最高海拔、最低海 拔与蛇类物种丰富度格局相关性很小, 因此本研究 支持能量假说，不支持生境异质性假说。

物种丰富度分布格局成因研究中虽然出现了 多种假说或者理论, 但仍然没有单一假说能充分解 释(Gaston, 2000; Cox \& Moore, 2010)。本研究表明 各种假说并不相互排斥, 而代表各假说的生态因子 共同影响中国蛇类物种丰富度格局。本研究使用空 间特征值模型的多元回归分析能够解释中国蛇类 物种丰富度总体 $56.5 \%$ 的变化, 尚有 $43.5 \%$ 不能解 释。其复杂性主要表现在以下三个方面。

首先，各假说中生态因子的复杂性。众多模型
中，小混合模型最能解释中国蛇类物种丰富格局， 因为它包括了在多元回归分析中所有 $P<0.05$ 的变 量。这说明物种丰富度格局影响因子多样, 而现有 的假说解释度低。如果进行赤池信息量准则的模型 选择时去除小混合模型, 得出的解释模型将依次是 水能动态假说、寒冷忍耐假说、环境能量假说及生 产力假说。出现这一情况的原因就是各假说中生态 因子成分的影响。很多生态因子之间关系密切, 各 假说之间也紧密联系(Allen et al, 2007; Wang et al, 2009), 各假说或模型受生态因子影响很大, 稍有不 慎则结果迥异, 如本研究中的大、小混合模型。因 此，应当重视各假说所包含影响因子的选择。建议 先参考前人的研究, 选择相关假说生态因子, 尽可 能全面获取生态因子数据及后各个生态因子的变 量(如最低值、最高值、平均值、变异系数等), 在统 计分析前根据需要去掉相关性高的因子(如本文去 掉相关性 $>0.7$ 的因子), 以免影响统计结果。

其次, 尺度复杂性。丰富度格局会随尺度变化, 局域尺度进程也影响区域尺度丰富度的观测 (Gaston, 2000)。尺度具有变异性, 各生态因子在不 同尺度表现出不同的特征(Fu et al, 2007; Gaston, 2000; Lü \& Fu, 2001), 即对物种多样性分布格局的 支持度, 也影响各假说对分布格局的解释(Hawkins et al, 2003a)。Hu et al (2005)分析了非环境类因子对 物种数目协同变化的影响发现, 不同鸟兽间的协同 变化不存在面积效应，但其空间尺度间的相关性差 异明显。本研究与后续各尺度的研究(结果另文发表) 表明在小尺度与较大尺度上物种丰富度格局影响 因子不同但存在关联, 局部尺度影响因子也会对区 域尺度产生影响(图 5)。因此将来需要研究不同尺度 对物种丰富度格局的影响, 以及不同尺度上各假说 对物种丰富度格局成因的解释。

最后, 人类因素影响的复杂性。人类因素影响 属于生物因子影响之一, 从生物干扰、食物竞争、 捕食等作用上直接或间接影响物种分布格局。Li \& Wllcove (2005)研究得出资源过度利用、生境破碎化 以及各种污染是我国两栖爬行动物濒危的主要原 因。另外, 人类生产生活导致的气候变化将影响动 物的行为和物候(Bull \& Vogt, 1979; Gargaglioni \& Milsom, 2007), 改变分布范围, 继而改变丰富度甚 至导致物种灭绝(Pounds et al, 1999; Sun \& Zhang, 2000)。蛇类具有重要的经济、科研价值, 尽管在 2000 年出版《国家保护的有益的或者有重要经济、 
科学研究价值的陆生野生动物名录》所列的中国 395 种爬行动物中, 蛇类就有 207 种, 是当时我国有 分布记录的所有蛇类，但我国蛇类受威胁程度很高， 几乎所有蛇的整体和器官都能作为中药、工艺、食 品材料 (Zhao, 2006)。因此, 必须重视人类因素对 我国蛇类丰富度格局的影响。

中国蛇类物种丰富度地理格局成因研究有 其复杂性, 因此, 在进一步研究中需要重视各假
说中影响因子的选择和人类活动的影响，并在不同 空间尺度上对蛇类物种丰富度地理格局进行综合 分析。

致谢: 感谢中国科学院成都生物研究所赵尔宓 院士提供中国早期蛇类研究文献，感谢宜宾学院郭 鹏教授、中国科学院成都生物研究所丁利博士等对 中国蛇类数据的修正。

\section{参考文献:}

Allen AP, Gillooly JF, Brown JH. 2007. Recasting the Species-Energy Hypothesis: The Different Roles of Kinetic and Potential Energy in Regulating Biodiversity $[\mathrm{M}] / /$ Storch D, Marquet PA, Brown JH. Scaling Biodiversity. Cambridge: Cambridge University Press, 283-299.

Bull JJ, Vogt RC. 1979. Temperature-dependent sex determination in turtles[J]. Science, 206(4423): 1186-1188.

Burnham KP, Anderson DR. 1998. Model Selection and Inference: A Practical Information-Theoretic Approach[M]. New York: Springer-Verlag

Connor EF, McCoy ED. 2001. Species-Area Relationships [M] // Levin SA. Encyclopedia of Biodiversity. New York: Academic Press, 397-411.

Cox CB, Moore PD. 2010. Biogeography: An Ecological and Evolutionary Approach. (8th ed)[M]. New Jersey: John Wiley \& Sons.

Currie DJ. 1991. Energy and large-scale patterns of animal- and plant-species richness[J]. Amer Nat, 137(1): 27-49.

Currie DJ, Mittelbach GG, Cornell HV, Field R, Guégan JF, Hawkins BA, Kaufman DM, Kerr JT, Oberdorff T, O'Brien E, Turner JRG. 2004. Predictions and tests of climate-based hypotheses of broad-scale variation in taxonomic richness[J]. Ecol Lett, 7(12): 1121-1134.

Currie DJ, Paquin V. 1987. Large-scale biogeographical patterns of species richness of trees[J]. Nature, 329(6137): 326-327.

Diniz-Filho JAF, Bini LM. 2005. Modelling geographical patterns in species richness using eigenvector-based spatial filters[J]. Glob Ecol Biogeogr, 14(2): 177-185

Evans KL, James NA, Gaston KJ. 2006. Abundance, species richness and energy availability in the North American avifauna[J]. Glob Ecol Biogeogr, 15(4): 372-385.

Fu CZ, Wang JX, Pu ZC, Zhang SL, Chen HL, Zhao B, Chen JK, Wu JH. 2007. Elevational gradients of diversity for lizards and snakes in the Hengduan Mountains, China[J]. Biod Conserv, 16(3): 707-726.

Gargaglioni LH, Milsom WK. 2007. Control of breathing in anuran amphibians[J]. Comp Biochem Physiol A, 147(3): 665-684.

Gaston KJ. 2000. Global patterns in biodiversity[J]. Nature, 405(6783): 220-227.

Gong SP, Wang HJ, Yang CT, Yu CS, Pan DS, Wang FM. 2010. Protobothrops cornutus discovered in Tianjingshan Forest, Guangdong Province, China[J]. Chn J Zool, 45(3): 170-173. [龚世平, 王海京, 杨 昌腾, 余春胜, 潘䒺生, 王付民. 2010. 广东天井山林区发现角原矛 头蝮. 动物学杂志, 45(3): 170-173.]

Gong SS. 2002. Historical variation and sustainable utilization of the Jianghan-Dongting Plain's wetlands[J]. Resour Environ Yangtze Basin, 11(6): 569-574. [龚胜生. 2002. 江汉一一洞庭湖平原湿地的历史变 迁与可持续利用. 长江流域资源与环境, 11(6): 569-574.]

Guisan A, Hofer U. 2003. Predicting reptile distributions at the mesoscale: relation to climate and topography[J]. J Bioger, 30(8): 1233-1243.
Guo P, Liu SY, Feng JC, He M. 2008. The Descriptionof a new species of Thermophis (Serpentes: Colubridae)[J]. Sichuan J Zool, 27(3): 321. [郭 鹏, 刘少英, 冯今朝, 何苗. 2008. 温泉蛇属 Thermophis 一新种四川温泉蛇. 四川动物, 27(3): 321.]

Guo P, Wang YZ. 2011. A new genus and species of cryptic Asian green pitviper (Serpentes: Viperidae: Crotalinae) from southwest China[J]. Zootaxa, 2918: 1-14.

Guo YH, Wu YK, He SP, Shi HT, Zhao EM. 2011. Systematics and molecular phylogenetics of Asian snail-eating snakes[J]. Zootaxa, 3001 57-64.

Hawkins BA. 2001. Ecology's oldest pattern?[J]. Endeavour, 25(3): 133-134.

Hawkins BA, Field R, Cornell HV, Currie DJ, Guégan JF, Kaufman DM, Kerr JT, Mittelbach GG, Oberdorff T, O'Brien EM, Porter EE, Turner JRG. 2003a. Energy, water, and broad-scale geographic patterns of species richness[J]. Ecology, 84(12): 3105-3117.

Hawkins BA, Porter EE, Diniz-Filho JAF. 2003b. Productivity and history as predictors of the latitudinal diversity gradient of terrestrial birds $[\mathrm{J}]$. Ecology, 84(6): 1608-1623.

He FL, Legendre P. 1996. On species-area relations[J]. Amer Nat, 148(4): 719-737.

Hu HJ, Jiang ZG, Wang ZW. 2005. Impacts of the non-environmental factors on covariance between avian and mammalian species richness[J]. Zool Res, 26(4): 358-364. [胡慧建, 蒋志刚, 王祖望. 2005. 非环境类因子 对物种数目协同变化的影响. 动物学研究, 26(4): 358-364]

Huang S, Ding L, Burbrink FT, Yan J, Huang JT, Ling C, Chen X, Zhang YP 2012. A new species of the genus Elaphe (Squamata: Colubridae) from Zoige County, Sichuan, China[J]. Asia Herpetol Res, 3(1): 38-45.

Huang Y, Dai D, Chen YY, Wan HF, Li JT, Wang YZ. 2011. Lizard species richness patterns in China and its environmental associations[J]. Biod Conserv, 20(7): 1399-1414.

Hutchinson GE. 1959. Homage to Santa Rosalia or why are there so many kinds of animals?[J]. Amer Nat, 93(870): 145-159.

Jiang F, Zhao EM. 2009. Gloydius lijianlii, a new species from the northern coastal islands along Shandong peninsula (Reptilia, Squamata, Viperidae)[J]. Acta Zootax Sin, 34(3): 642-646. [江帆，赵尔宓. 2009. 山东半岛北部沿岸岛屿蝮属一新种(爬行纲, 有鳞目,蛏科). 动物分 类学报, 34(3): 642-646.]

Jiang ZG, Ma KP, Han XG. 1997. Conservation Biology[M]. Zhejiang: Zhejiang Science and Technology Press. [蒋志刚, 马克平, 韩兴国. 1997. 保护生物学. 杭州: 浙江科学技术出版社.]

Kerr JT, Packer L. 1997. Habitat heterogeneity as a determinant of mammal species richness in high-energy regions[J]. Nature, 385(6613): 252-254.

Kiester AR. 1971. Species density of North American amphibians and reptiles[J]. Syst Zool, 20(2): 127-137. 
Li YM, Wllcove DS. 2005. Threats to vertebrate species in China and the United States[J]. BioScience, 55(2): 147-153.

Lin X, Wang ZH, Tang ZY, Zhao SQ, Fang JY. 2009. Geographic patterns and environmental correlates of terrestrial mammal species richness in China[J]. Biodiv Sci, 17(6): 652-663. [林金金，王志恒，唐志尧，赵淑清， 方精云. 2009. 中国陆栖哺乳动物物种丰富度的地理格局及其与环 境因子的关系. 生物多样性, 17(6): 652-663.]

Lin ZH, Mo XG. 2011. Interactions between evolution of farming systems and environment for agricultural production in the Huang-Huai-Hai Plain during the historic period[J]. Chn J Eco-Agricul, 19(5): 1072-1079. [林忠辉, 莫兴国. 2011. 历史时期黄淮海平原农作制度 变迁与农业生产环境演变. 中国生态农业学报, 19(5): 1072-1079.]

Luo J, Ryabov SA, Luo Y, Gao HY, Luo ZR, Hu XC. 2010. Classification and distribution of the Genus Dinodon[J]. Sichuan J Zool, 29(4): 579-582, 677. [罗键, Ryabov SA, 罗颖, 高红英, 罗至仁, 胡先成. 2010. 链蛇属的分类分布现状. 四川动物, 29(4): 579-582, 677.]

Lü YH, Fu BJ. 2001. Ecological scale and scaling[J]. Acta Ecol Sin, 21(12): 2096-2105. [吕一河, 傅伯杰. 2001. 生态学中的尺度及尺度转换方 法. 生态学报, 21(12): 2096-2105.]

Malhotra A, Dawson K, Guo P, Thorpe RS. 2011. Phylogenetic structure and species boundaries in the mountain pitviper Ovophis monticola (Serpentes: Viperidae: Crotalinae) in Asia[J]. Molec Phylo Evol, 59(2): 444-457.

O'Brien EM. 1993. Climatic gradients in woody plant species richness: towards an explanation based on an analysis of southern Africa's woody flora[J]. J Bioger, 20(2): 181-198.

Pianka ER. 1966. Latitudinal gradients in species diversity: a review of concepts[J]. Amer Nat, 100(910): 33-46.

Pounds JA, Fogden MPL, Campbell JH. 1999. Biological response to climate change on a tropical mountain[J]. Nature, 398(6728): 611-615.

Qian H, Wang XH, Wang SL, Li YL. 2007. Environmental determinants of amphibian and reptile species richness in China[J]. Ecography, 30(4): 471-482.

Rahbek C. 2005. The role of spatial scale and the perception of large-scale species-richness patterns[J]. Ecol Lett, 8(2): 224-239.

Rangel TF, Diniz-Filho JAF, Bini LM. 2010. SAM: a comprehensive application for spatial analysis in macroecology[J]. Ecography, 33(1): 46-50.

Rangel TFLVB, Diniz-Filho JAF, Bini LM. 2006. Towards an integrated computational tool for spatial analysis in macroecology and biogeography[J]. Glo Ecol Biog, 15(4): 321-327.

Rao DQ, Zhao EM. 2005. A new record from China- Protobothrops Kaulbacki (Reptilia, Serpentes, Viperidae)[J]. Acta Zootax Sin, 30(1): 209-211. [饶定齐, 赵尔宓. 2005. 中国一新纪录种——缅北原矛头 蝮 (爬行纲, 蛇亚目, 蛏科). 动物分类学报, 30(1): 209-211.]

Ricklefs RE, Schluter D. 1993. Species Diversity in Ecological Communities: Historical and Geographical Perspectives[M]. Chicago: University of Chicago Press.

Rodríguez MÁ, Belmontes JA, Hawkins BA. 2005. Energy, water and large-scale patterns of reptile and amphibian species richness in Europe[J]. Acta Oecol, 28(1): 65-70.

Schall JJ, Pianka ER. 1978. Geographical trends in numbers of species[J]. Science, 201(4357): 679-686

Shen GS. 1985. Fuzzy cluster analyses to the geographical distribution of Amphibians and Reptiles in China[J]. Sichuan J Zool, 4(2): 13-16. [沈 国坤. 1985. 中国两栖爬行动物地理分布的模糊聚类分析. 四川动 物, 4(2): 13-16.]

Sun QH, Zhang ZW. 2000. The impact of Climate warming on the distribution of Chinese Birds[J]. Chn J Zool, 35(6): 45-48. [孙全辉, 张 正旺. 2000. 气候变暖对我国鸟类分布的影响. 动物学杂志, 35(6): 45-48.]

Sun RY. 2001. Principles of Animal Ecology. (4th ed)[M]. Beijing: Beijing Normal University Publishing Group. [孙儒泳. 2001. 动物生态学原
理. (第四版)[M]. 北京: 北京师范大学出版社.]

Terribile LC, Diniz-Filho JAF. 2009. Spatial patterns of species richness in New World coral snakes and the metabolic theory of ecology[J]. Acta Oecol, 35(2): 163-173.

Terribile LC, Olalla-Tárraga MÁ, Morales-Castilla I, Rueda M, Vidanes RM, Rodríguez MÁ, Diniz-Filho JAF. 2009. Global richness patterns of venomous snakes reveal contrasting influences of ecology and history in two different clades[J]. Oecologia, 159(3): 617-626.

Turner JRG. 2004. Explaining the global biodiversity gradient: energy, area, history and natural selection[J]. Basic Appl Ecol, 5(5): 435-448.

Turner JRG, Gatehouse CM, Corey CA. 1987. Does solar energy control organic diversity? Butterflies, moths and the British climate[J]. Oikos, 48(2): 195-205.

Vogel G, David P. 2010. A new species of the genus Lycodon (Boie, 1826) from Yunnan Province, China (Serpentes: Colubridae)[J]. Bonn Zool Bull, 57(2): 289-296.

Vogel G, Luo J. 2011. A new species of the genus Lycodon (Boie, 1826) from the southwestern mountains of China (Squamata: Colubridae)[J]. Zootaxa, 2807: 29-40.

von Humboldt A. 1808. Ansichten der Natur: Mit Wissenschaftlichen Erläuterungen[M]. Tübingen: J. G. Cotta'schen Buchhandlung.

Wang CH. 2004. Reseach on the Biodiversity Distribution Patterns in Mainland of China[D]. Ph.D. dissertation, Shanxi University, Taiyuan. [王翠红. 2004. 中国陆地生物多样性分布格局的研究. 山西大学博 十论文]

Wang ZH, Tang ZY, Fang JY. 2009. The species-energy hypothesis as a mechanism for species richness patterns[J]. Biodiv Sci, 17(6): 613-624. [王志恒, 唐志尧, 方精云. 2009. 物种多样性地理格局的能量假说. 生物多样性, 17(6): 613-624.]

Wiens JJ, Donoghue MJ. 2004. Historical biogeography, ecology and species richness[J]. Trends Ecol Evol, 19(12): 639-644.

Willis KJ, Whittaker RJ. 2002. Species diversity-scale matters[J]. Science, 295(5558): 1245-1248.

Wright DH. 1983. Species-energy theory: an extension of species-area theory[J]. Oikos, 41(3): 496-506.

Yang JH, Orlov N, Wang YY. 2011a. A new species of pitviper of the genus Protobothrops from China (Squamata: Viperidae)[J]. Zootaxa, 2936: 59-68.

Yang JH, Wang YY, Zhang B, Lau MW, Chou WH. 2011b. Revision of the diagnostic characters of Opisthotropis maculosa Stuart and Chuaynkern, 2007 with notes on its distribution and variation, and a key to the genus Opisthotropis (Squamata: Natricidae)[J]. Zootaxa, 2785: 61-68.

Zhang J, Jiang K, Vogel G, Rao DQ. 2011a. A new species of the genus Lycodon (Squamata, Colubridae) from Sichuan Province, China[J]. Zootaxa, 2982: 59-68.

Zhang L, Jiang K, Hu P, Yu BC, Peng YB, Tang XP, Hu HJ. 2011b. Lycodon futsingensis: a new snake record in Guangdong priovince, China[J]. Chn J Zool, 46(1): 128-130. [张亮, 蒋珂, 胡平，遇宝成，彭永波，唐 小平, 胡慧建. 2011. 广东省蛇类新纪录——福清白环蛇. 动物学 杂志, 46(1): 128-130.]

Zhang RZ. 1999. Zoogeography of China[M]. Beijing: Science Press. [张荣 祖. 1999. 中国动物地理. 北京: 科学出版社.]

Zhao EM. 2006. Snake of China[M]. Hefei: Anhui Science and Technology Publishing House. [赵尔宓. 2006. 中国蛇类. 合肥: 安徽科学技术出 版社.]

Zhao EM, Adler K. 1993. Herpetology of China[M]. Oxford, Ohio: Society for the Study of Amphibians and Reptiles in cooperation with Chinese Society for the Study of Amphibians and Reptiles.

Zhao QG, Huang GQ, Qian HY. 2007. Ecological environment and Sustainable development of poyang lake[J]. Acta Pedol Sin, 44(2): 318-326. [赵其国, 黄国勤, 钱海燕. 2007. 鄱阳湖生态环境与可持续 发展. 土壤学报, 44(2): 318-326.] 


\section{3 年部分生命科学学术期刊联合征订表}

\begin{tabular}{|c|c|c|c|c|}
\hline 刊物名称 & 邮发代号 & 刊 期 & 期刊网址 & 编辑部 E-mail \\
\hline 癌变·畸变·突变 & $80-285$ & 双月刊 & http://www.egh.net.cn & cemsctm@stu.edu.cn \\
\hline 病毒学报 & $82-227$ & 双月刊 & http://bdxb.cbpt.cnki.net & bdxb@chinajournal.net.cn \\
\hline 动物分类学报 & $2-154$ & 季 刊 & http://www.zootax.com.cn & yangn@ioz.ac.cn \\
\hline 动物学研究 & $64-20$ & 双月刊 & http://www.zoores.ac.cn & zoores@mail.kiz.ac.cn \\
\hline 动物学杂志 & $2-422$ & 双月刊 & http://dwxzz.ioz.ac.cn & journal@ioz.ac.cn \\
\hline 分子植物育种 & $84-23$ & 双月刊 & http://5th.sophiapublisher.com & mpb@hibio.org \\
\hline 国际遗传学杂志 & $14-55$ & 双月刊 & http//www.cma.org.cn & genetics2006@163.com \\
\hline 基因组学与应用生物学 & $48-213$ & 双月刊 & http://www.genoapplbiol.org & gab@hibio.org \\
\hline 菌物学报 & $2-499$ & 双月刊 & http://journals.im.ac.cn/jwxtcn & jwxt@im.ac.cn \\
\hline 昆虫学报 & $2-153$ & 月 刊 & http//www.insect.org.cn & kcxb@ioz.ac.cn \\
\hline 林业科学 & $82-6$ & 月 刊 & http://www.linyekexue.net & linykx@forestry.ac.cn \\
\hline 林业科学研究 & $80-717$ & 双月刊 & http://www.lykxyj.com & lykxyj@caf.ac.cn \\
\hline 农业生物技术学报 & $2-367$ & 月 刊 & http//www.jabiotech.org.cn/ & nsjxb@cau.edu.cn \\
\hline 人类学学报 & $2-384$ & 季 刊 & http//www.ivpp.ac.cn & acta@ivpp.ac.cn \\
\hline 生命科学 & $4-628$ & 月 刊 & http://www.lifescience.net.cn & cbls@sibs.ac.cn \\
\hline 生命科学研究 & $42-172$ & 双月刊 & http://smky.cbpt.cnki.net & life@hunnu.edu.cn \\
\hline 生物多样性 & $82-858$ & 双月刊 & http//www.biodiversity-science.net & biodiversity@ibcas.ac.cn \\
\hline 生物工程学报 & $82-13$ & 月 刊 & http://journals.im.ac.cn/cjbcn & cjb@im.ac.cn \\
\hline 生物化学与生物物理进展 & $2-816$ & 月 刊 & http//www.pibb.ac.cn & prog@sun5.ibp.ac.cn \\
\hline 生物技术通讯 & $82-196$ & 双月刊 & http://swtx.chinajournal.net.cn & swtx@263.net \\
\hline 兽类学报 & $56-11$ & 季 刊 & http://www.mammal.cn/ & slxb@nwipb.ac.cn \\
\hline 水生生物学报 & $82-329$ & 双月刊 & http://ssswxb.ihb.ac.cn & acta@ihb.ac.cn \\
\hline 微生物学报 & $2-504$ & 月 刊 & http://journals.im.ac.cn/actamicrocn & actamicro@im.ac.cn \\
\hline 微生物学通报 & $2-817$ & 月 刊 & http://journals.im.ac.cn/wswxtben & tongbao@im.ac.cn \\
\hline 畜牧兽医学报 & $82-453$ & 月 刊 & http//www.xmsyxb.com & xmsyxb@263.net \\
\hline 遗传 & $2-810$ & 月 刊 & http://www.chinagene.cn & yczz@genetics.ac.cn \\
\hline 遗传学报 & $2-819$ & 月 刊 & http://www.jgenetgenomics.org & jgg@genetics.ac.cn \\
\hline 应用昆虫学报 & $2-151$ & 双月刊 & http//www.ent-bull.com.cn & entom@ioz.ac.cn \\
\hline 应用与环境生物学报 & $62-15$ & 双月刊 & http//www.cibj.com & biojaeb@cib.ac.cn \\
\hline 植物分类与资源学报 & $64-11$ & 双月刊 & http://journal.kib.ac.cn & bianji@mail.kib.ac.cn \\
\hline 植物科学学报 & $38-103$ & 双月刊 & http://www.plantscience.cn & editor@wbgcas.cn \\
\hline 植物学报 & $2-967$ & 双月刊 & http://www.chinbullbotany.com & cbb@ibcas.ac.cn \\
\hline 《中国农业科学》中文版 & $2-138$ & 半月刊 & http://www.chinaagrisci.com & zgnykx@mail.caas.net.cn \\
\hline 《中国农业科学》英文版 & $10-1039$ & 月 刊 & http://www.chinaagrisci.com & zgnykx@mail.caas.net.cn \\
\hline 中国生态农业学报 & $82-973$ & 月 刊 & http://www.ecoagri.ac.cn & editor@sjziam.ac.cn \\
\hline 中国生物工程杂志 & $82-673$ & 月 干刂 & http//www.biotech.ac.cn & biotech@mail.las.ac.cn \\
\hline 中国生物化学与分子生物学报 & $82-312$ & 月 刊 & http//cjbmb.bjmu.edu.cn & shxb@bjmu.edu.cn \\
\hline 中国实验动物学报 & $2-748$ & 双月刊 & http://zgsydw.alljournal.ac.cn & A67761337@126.com \\
\hline 中国水产科学 & $18-250$ & 双月刊 & http//www.fishscichina.com & zgsckx@cafs.ac.cn \\
\hline 中国水稻科学 & $32-94$ & 双月刊 & http://www.ricesci.cn & cjrs@263.net \\
\hline 中国细胞生物学学报 & $4-296$ & 月 刊 & http://www.cjcb.org & cjcb@sibs.ac.cn \\
\hline 作物学报 & $82-336$ & 月 刊 & http://www.chinacrops.org/zwxb & zwxb301@mail.caas.net.cn \\
\hline
\end{tabular}

